\title{
PRODUTIVIDADE E QUALIDADE DE CANA-DE-AÇÚCAR CULTIVADA EM SOLO TRATADO COM LODO DE ESGOTO, VINHAÇA E ADUBOS MINERAIS
}

\author{
LUIZ C. TASSO JÚNIOR ${ }^{1}$, MARCOS O. MARQUES ${ }^{2}$, ADEMIR FRANCO ${ }^{3}$, \\ GUSTAVO DE A. NOGUEIRA ${ }^{4}$, FÁBIO O. DE NOBILE ${ }^{5}$, FÁBIO CAMILOTTI ${ }^{6}$, \\ ALYSSON R. DA SILVA ${ }^{6}$
}

\begin{abstract}
RESUMO: O uso agrícola de resíduos orgânicos, de origem agrícola, urbana ou industrial, é uma interessante alternativa de disposição, permitindo a reciclagem de nutrientes (NPK) nos ecossistemas. Este trabalho avaliou o efeito da aplicação de lodo de esgoto como fonte de $\mathrm{N}$ e de vinhaça como fonte de $\mathrm{K}$ comparado ao uso de fontes minerais desses nutrientes sobre a produtividade e variáveis agroindustriais da cana-de-açúcar, por dois anos consecutivos (cana-planta e cana-soca). O experimento foi conduzido em Latossolo Vermelho-Amarelo distrófico típico, em Pontal - SP, e a variedade de cana-de-açúcar avaliada foi a SP 81-3250. Utilizou-se de esquema fatorial 3x2x2+1, ou seja, três tipos de resíduos (lodo de esgoto $+\mathrm{KCl}$; vinhaça + uréia, e lodo de esgoto + vinhaça); dois modos de aplicação (na linha de plantio ou em área total); duas doses (100 e 200\% do N e K necessários à cultura) e um tratamento adicional com adubação mineral, sendo os tratamentos distribuídos na área em blocos ao acaso, com três repetições. Foram avaliadas a produtividade e as variáveis agroindustriais ( ${ }^{\circ}$ brix, pol no caldo, fibra, pureza, pol na cana, AR e ATR). As produtividades de colmo e de açúcar para cana-planta foram mantidas quando $\mathrm{N}$ e $\mathrm{K}$ foram fornecidos pelo lodo de esgoto e vinhaça, respectivamente. A cana-soca apresentou maior produtividade de colmo e de açúcar quando foram utilizados os resíduos separadamente, complementados com fontes minerais. Quanto ao modo de aplicação, não foram observadas diferenças significativas para as variáveis analisadas.
\end{abstract}

PALAVRAS-CHAVE: Saccharum spp., adubação nitrogenada e potássica, resíduos orgânicos.

\section{YIELD AND QUALITY OF SUGAR CANE CULTIVATED IN SEWAGE SLUDGE, VINASSE AND MINERAL FERTILIZATION SUPPLIED SOIL}

\begin{abstract}
The agricultural use of organic residues is an interesting alternative to disposal allowing the recycling of nutrients (NPK) in the ecosystems. The objective of this research was to evaluate the effect of sludge application as $\mathrm{N}$ source and vinasse as $\mathrm{K}$ source when compared to the use of mineral sources of these nutrients on yield and technological variables of the sugar cane, over two consecutive years (cane-plant and first ratoon cane). The experiment was conducted on a Haplustox, in Pontal county, São Paulo state, Brazil. The sugarcane variety was SP 81-3250. The results were organized in a factorial scheme $3 \times 2 \times 2+1$ : three residue types (sewage sludge $+\mathrm{KCl}$, vinasse + urea and sewage sludge + vinasse); two application mode (planting line and total area); two doses (100 and $200 \%$ of $\mathrm{N}$ and $\mathrm{K}$ for sugarcane crop) and an additional treatment (mineral fertilization). The experimental design was a randomized blocks with three replications. The analyzed parameters were productivity and technological variables (juice brix, juice sucrose contents, reducing sugars juice contents, purity, cane sucrose contents, and recoverable total sugar (RTS) cane contents and RTS productivity). The stalks and the sugar yields of cane-plant did not change while the $\mathrm{N}$ and $\mathrm{K}$ were suplyied by the sludge and by vinasse, respectively. The first ratoon cane presented greater stalks and sugar yield when residue were used separated complemented by mineral fertilization. In relation to application mode, no differences were observed for all paremeters.
\end{abstract}

KEYWORDS: Saccharum spp., nitrogen and potassium fertilizers, organic residues.

\footnotetext{
${ }^{1}$ Doutorando em Agronomia, Departamento de Tecnologia, UNESP, Jaboticabal - SP, lctasso@ yahoo.com.br, Bolsista da CAPES.

${ }^{2}$ Prof. Adjunto, Departamento de Tecnologia, UNESP, Jaboticabal - SP.

${ }^{3}$ Doutorando em Agronomia, CENA, USP, Piracicaba - SP.

${ }^{4}$ Mestrando em Agronomia, Departamento de Fitotecnia, UNESP, Jaboticabal - SP.

${ }^{5}$ Doutorando em Agronomia, Departamento de Engenharia Rural, UNESP, Jaboticabal - SP.

${ }^{6}$ Doutorando em Agronomia, Departamento de Solos e Adubos, UNESP, Jaboticabal - SP.

Recebido pelo Conselho Editorial em: 20-7-2005
}

Aprovado pelo Conselho Editorial em: 14-2-2007 


\section{INTRODUÇÃO}

Com o crescimento populacional, em sua ampla maioria urbana, e o aumento do desenvolvimento industrial, têm sido gerados águas residuárias e resíduos sólidos em grandes quantidades. $\mathrm{O}$ tratamento dessas águas residuárias origina um material pastoso, denominado lodo de esgoto, que é constituído de matéria orgânica, água e elementos minerais. Melhorias nas propriedades físicas, químicas e biológicas do solo têm sido atribuídas à aplicação de lodo de esgoto, assim como desenvolvimento, estado nutricional, principalmente no que se refere ao fornecimento de $\mathrm{N}$, e produtividade das plantas de interesse econômico semelhantes, ou mesmo superiores, ao promovido pelo manejo agrícola convencional (MELO et al., 2001 e ABREU JÚNIOR et al., 2005). Na cultura da cana-de-açúcar, os dados da literatura têm enfatizado benefícios à produtividade agrícola e ao rendimento em sacarose (SILVA et al., 1998). CHIBA (2005), aplicando $16 \mathrm{t} \mathrm{ha}^{-1}$ de lodo de esgoto em cana-soca, em combinação com o adubo nitrogenado, concluiu que o lodo pode substituir $100 \%$ do adubo nitrogenado.

Dentre os resíduos gerados na industrialização da cana, destaca-se a vinhaça. No Brasil, sua importância resulta não só do grande volume em que é gerada (12 a 15 vezes o volume de álcool produzido, segundo BUZOLIN, 1997), mas também da economia de insumos que se obtêm com a prática do seu aproveitamento na forma de fertilizante e/ou como condicionadora de solos, em sua maioria, cultivados com cana-de-açúcar. Na fração mineral, integrando a composição química da vinhaça, o potássio é o elemento predominante. Os teores normalmente encontrados variam de acordo com o tipo de mosto que foi fermentado. ORLANDO FILHO et al. (1983) quantificaram os níveis de potássio em vinhaças de origens diversas e encontraram os seguintes valores expressos em $\mathrm{kg}$ de $\mathrm{K}_{2} \mathrm{O} \mathrm{m}^{-3}: 1,15$ a 1,94 (mosto de caldo), 2,18 a 3,34 (mosto de misto) e 3,95 a 7,59 (mosto de melaço).

É importante pesquisar se a fertilização com tais resíduos pode ser comparável à adubação mineral em termos de produtividade e qualidade dessa cultura. CAMILOTTI et al. (2006) constataram que o lodo de esgoto como fonte de $\mathrm{N}$ e vinhaça como fonte de $\mathrm{K}$ também foram eficientes como fontes minerais desses dois nutrientes (uréia e $\mathrm{KCl}$ ) na produtividade e na qualidade industrial de cana-soca de $3^{\underline{0}}$ e $4^{\underline{0}}$ cortes.

O objetivo deste trabalho foi comparar o efeito do lodo de esgoto $+\mathrm{KCl}$ e da vinhaça + uréia na produtividade agrícola e em variáveis agroindustriais da cana-de-açúcar (Saccharum spp.) cultivada por dois anos consecutivos (cana-planta e cana-soca).

\section{MATERIAL E MÉTODOS}

A variedade de cana-de-açúcar empregada como planta-teste foi a SP81-3250. O experimento foi instalado em 7 de abril de 2000, em propriedade da Destilaria Santa Inês Ltda., no Município de Pontal - SP, em um Latossolo Vermelho distroférrico, com os seguintes atributos químicos avaliados antes da instalação do experimento: $\mathrm{pH}$ em $\mathrm{CaCl}_{2}=5,0$; matéria orgânica $=25 \mathrm{~g} \mathrm{dm}^{-3}$; $\mathrm{P}=20 \mathrm{mg} \mathrm{dm}{ }^{-3} ; \mathrm{K}=1,2 ; \mathrm{Ca}=20 ; \mathrm{Mg}=6 ; \mathrm{H}+\mathrm{Al}=28 ; \mathrm{SB}=27,2 ; \mathrm{T}=55,2 \mathrm{mmol}_{\mathrm{c}} \mathrm{dm}^{-3}, \mathrm{e}$ $\mathrm{V}=49 \%$. Segundo os critérios estabelecidos por RAIJ et al. (1996), trata-se de solo com acidez elevada e baixa saturação por bases e teores de K. Entretanto, P e Mg apresentam-se com teores médios e Ca com teores elevados.

O lodo de esgoto utilizado foi obtido junto à SABESP - Estação de Tratamento de Esgotos de Franca - SP, e a vinhaça obtida junto à Destilaria Santa Inês, Pontal - SP. A vinhaça empregada foi obtida a partir da destilação de vinho resultante da fermentação de caldo, em aparelho convencional de destilação, nas instalações da Destilaria Santa Inês Ltda. Os resultados estão apresentados na Tabela 1. 
TABELA 1. Composições químicas parciais do lodo de esgoto (base seca) e da vinhaça empregados no experimento. Média de três repetições.

\begin{tabular}{|c|c|c|c|c|c|c|c|c|c|}
\hline Resíduo & $\mathrm{N}$ & $\mathrm{P}$ & $\mathrm{K}$ & $\mathrm{Ca}$ & $\mathrm{Mg}$ & $\mathrm{Cu}$ & $\mathrm{Mn}$ & $\mathrm{Zn}$ & $\mathrm{Fe}$ \\
\hline Lodo de esgoto & ----- & ------- & $\mathrm{g} \mathrm{kg}^{-1}$ & 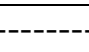 & ---- & ----- & ----1 & $\mathrm{~g}^{-1}---$ & \\
\hline Cana-planta & 79,50 & 10,60 & 0,63 & $\mathrm{nd}^{*}$ & nd* & 225 & 400 & 1000 & 26 \\
\hline Cana-soca & 52,00 & 3,40 & 1,96 & 4,25 & 0,56 & $\mathrm{nd}^{*}$ & nd* & $\mathrm{nd}^{*}$ & 29 \\
\hline Vinhaça & ----. & 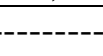 & $\mathrm{kg} \mathrm{m}^{-3}$ & & & & & & \\
\hline Cana-planta & 0,35 & 0,13 & 1,39 & 0,42 & 0,07 & 1 & 5 & 1 & 60 \\
\hline Cana-soca & 0,29 & 0,20 & 1,11 & 0,85 & 0,22 & 1 & 4 & 1 & 63 \\
\hline
\end{tabular}

* nd: não-determinado.

Os tratamentos testados foram em número de 13, resultantes da combinação de três tipos de resíduos (lodo de esgoto; vinhaça; lodo de esgoto + vinhaça), com dois modos de aplicação (linha e entre-linha) e com duas doses (o lodo de esgoto, visando ao fornecimento de 100 e $200 \%$ do nitrogênio necessário para a cultura, e a vinhaça, visando ao fornecimento de 100 e $200 \%$ do potássio necessário para a cultura). Empregou-se um tratamento adicional (testemunha), cujas parcelas receberam calagem e fertilização mineral de acordo com as recomendações constantes do Boletim n⿳ 100 do IAC, (RAIJ et al., 1996) para o Estado de São Paulo.

Adotou-se o delineamento experimental em blocos casualizados, com 13 tratamentos e três repetições, totalizando 39 parcelas. Cada parcela experimental constituiu-se de cinco linhas de cana espaçadas de 1,50 m entre si e com $10 \mathrm{~m}$ de comprimento.

As doses utilizadas foram 5 e $10 \mathrm{t} \mathrm{ha}^{-1}$ de lodo de esgoto e 115 e $230 \mathrm{~m}^{3} \mathrm{ha}^{-1}$ de vinhaça, na cana-planta, e 7 e $14 \mathrm{t} \mathrm{ha}^{-1}$ de lodo de esgoto e 117 e $234 \mathrm{~m}^{3} \mathrm{ha}^{-1}$ de vinhaça na $1^{\mathrm{a}}$ cana-soca, para as doses de 100 e $200 \%$, respectivamente. As doses de N e K empregadas foram baseadas na recomendação de SPIRONELLO et al. (1997), constando de $100 \mathrm{~kg} \mathrm{ha}^{-1}$ de $\mathrm{N}$ e $130 \mathrm{~kg} \mathrm{ha}^{-1}$ de $\mathrm{K}_{2} \mathrm{O}$ para cada um dos dois anos de cultivo. As concentrações de $\mathrm{N}$ no lodo de esgoto e de $\mathrm{K}$ na vinhaça (Tabela 1) serviram de base para o cálculo da quantidade do resíduo a ser aplicada para fornecer 100 e $200 \%$ da dose recomendada de cada um desses nutrientes para cana-soca.

Vários são os fatores que interferem na percentagem de $\mathrm{N}$ disponível para as plantas presente no lodo de esgoto: sistema de tratamento a que foi submetido o esgoto, sistema de estabilização do lodo gerado, percentagem de $\mathrm{N}^{-\mathrm{NO}_{3}^{-}}$e $\mathrm{N}^{-\mathrm{NH}_{4}^{+}}$e método de aplicação no solo (FRANKLIN, 2004). Na maior parte dos casos, esse valor oscila entre 30 e $35 \%$, mas pode chegar até $50 \%$ em casos isolados. Neste trabalho, considerou-se de $33 \%$ a percentagem de $\mathrm{N}$ disponível às plantas presente nos lodos empregados. Na cana-soca, as doses foram calculadas em função da análise de solo realizada após a colheita da cana-planta nas parcelas do tratamento-testemunha, onde os seguintes resultados foram obtidos: $\mathrm{pH}$ em $\mathrm{CaCl}_{2}=4,7$; matéria orgânica $=24 \mathrm{~g} \mathrm{dm}^{-3} ; \mathrm{P}=$ $10 \mathrm{mg} \mathrm{dm}{ }^{-3} ; \mathrm{K}=0,8 ; \mathrm{Ca}=25 ; \mathrm{Mg}=7 ; \mathrm{H}+\mathrm{Cl}=64 ; \mathrm{SB}=32,8 ; \mathrm{T}=96,8 \mathrm{mmol}_{\mathrm{c}} \mathrm{dm}^{-3} ; \mathrm{V}=34 \%$. Assim, para o cultivo da $1^{\underline{a}}$ cana-soca, foi aplicado calcário dolomítico na dose de $1,8 \mathrm{t} \mathrm{ha}^{-1}$, conforme recomendação de RAIJ et al. (1996). O lodo de esgoto foi complementado com potássio (cloreto de potássio), e a vinhaça, com nitrogênio (uréia). Para o cultivo realizado nos dois ciclos da cultura, empregou-se cultivador de uma haste com ponteiras aletadas. A cultura foi mantida livre de competição de plantas daninhas por meio da aplicação de herbicidas (tebuthuiron, hexazinone + diuron).

A amostragem de cana (dez colmos coletados aleatoriamente na área útil de cada parcela) foi realizada uma semana antes da colheita. A área útil de cada parcela foi estabelecida como sendo a área ocupada pelas três linhas centrais, descartando $1 \mathrm{~m}$ de cada extremidade.

Nas amostras coletadas, após pesagem, as avaliações realizadas consistiram na determinação das seguintes variáveis agroindustriais: ${ }^{\circ}$ brix, pol no caldo, pol na cana, pureza, fibra, AR (açúcar redutor) e ATR (açúcar total recuperável), de acordo com a metodologia proposta pelo CONSECANA (2003). 
A produção de colmos foi quantificada por meio da pesagem dos colmos da área útil de cada parcela acrescida do peso dos dez colmos retirados por ocasião da amostragem. Dessa forma, considerando esses resultados e a área útil de cada parcela, calculou-se a produtividade de colmos, expressa em $\mathrm{t} \mathrm{ha}^{-1}$.

Os resultados obtidos foram agrupados e submetidos à análise de variância. Nos casos pertinentes, procedeu-se à comparação de médias, pelo teste de Tukey, a 5\% de probabilidade.

\section{RESULTADOS E DISCUSSÃO}

Os dados de produtividade da cana-planta e $1^{\text {a }}$ cana-soca estão apresentados na Tabela 2. A produtividade da cana-planta revela a não-ocorrência de efeitos ocasionados pelos fatores de variação, ou seja, a utilização dos resíduos em qualquer uma das combinações estudadas resulta em produtividades agrícolas nos mesmos níveis daquelas obtidas com a fertilização mineral.

Resultados semelhantes foram obtidos por MARQUES (1996) em Latossolo VermelhoEscuro aplicando doses 10; 20 e $40 \mathrm{t} \mathrm{ha}^{-1}$ de lodo de esgoto e por OLIVEIRA (2000), aplicando doses de 33; 66 e $99 \mathrm{t} \mathrm{ha}^{-1}$ de lodo de esgoto em Latossolo Vermelho-Amarelo. No segundo ano de cultivo ( $1^{\underline{a}}$ cana-soca), observa-se que as maiores produtividades são encontradas quando se emprega lodo de esgoto complementado com $\mathrm{KCl}$, sendo esses valores da mesma ordem de grandeza daqueles obtidos com a fertilização mineral (Tabela 2). CAMILOTTI et al. (2006) não encontraram diferenças na produtividade da cana-de-açúcar de $3^{\underline{0}}$ e $4^{0}$ cortes utizando a mesma variedade do presente estudo, adubada com lodo de esgoto + KCL e vinhaça + uréia. SILVA et al. (1998) verificam ganhos de produtividade de biomassa de colmos em conseqüência do uso de até $30 \mathrm{t} \mathrm{ha}^{-1}$ de lodo. Segundo MARQUES (1996), a decomposição gradativa da matéria orgânica do lodo de esgoto no solo aumenta a possibilidade de aproveitamento do $\mathrm{N}$ disponibilizado pelas plantas, comparado ao fornecimento pelo adubo mineral que é prontamente disponível. Considerando que o lodo de esgoto apresenta $10-20 \%$ da decomposição no segundo ano (ANDREOLI et al., 1997), supõe-se que o $\mathrm{N}$ seria o fator limitante para a produção menor no tratamento com vinhaça complementada com uréia.

TABELA 2. Produtividade média $\left(\mathrm{t} \mathrm{ha}^{-1}\right)$ e resultados da análise de variância para cana-de-açúcar (cana-planta e cana-soca) cultivada por dois anos consecutivos.

\begin{tabular}{lcc}
\hline & Cana-Planta & Cana-Soca \\
\hline Fertilização mineral & 125,7 & 105,6 \\
Fatorial & 125,5 & 100,0 \\
\hline Lodo de esgoto + KCl & 124,0 & $106,6^{\mathrm{A}}$ \\
Vinhaça + uréia & 125,9 & $94,3^{\mathrm{B}}$ \\
Lodo de esgoto + vinhaça & 126,5 & $99,3^{\mathrm{AB}}$ \\
\hline Localizada & 125,8 & 99,7 \\
Área total & 125,2 & 100,3 \\
\hline Dose 100\% & 124,6 & 98,2 \\
Dose 200\% & 126,4 & 101,9 \\
\hline
\end{tabular}

Teste F

Fertilização mineral vs Fatorial $\quad 0,01^{\mathrm{NS}} \quad 0,85^{\mathrm{NS}}$

Resíduos

$0,40^{\mathrm{NS}} \quad 4,46^{*}$

Modo de aplicação $\quad 0,22^{\mathrm{NS}} \quad 0,03^{\mathrm{NS}}$

Doses $0,09^{\mathrm{NS}} \quad 1,16^{\mathrm{NS}}$

\begin{tabular}{lcc}
\hline C.V. $(\%)$ & 7,43 & 10,10
\end{tabular}

NS - não-significativo; * diferença significativa a $5 \%$ de probabilidade - $\mathrm{p}<0,05$; médias seguidas de letras iguais ou sem letras não diferem entre si, pelo Teste de Tukey, a 5\% de probabilidade; C.V. (\%) - coeficiente de variação.

O modo de aplicação dos resíduos (na linha de plantio ou ao lado da linha e em área total) e o aumento da dose em $100 \%$ não afetaram a produtividade, tanto da cana-plana quanto da soqueira, 
indicando que a disponibilidade gradual do $\mathrm{N}$ possibilita seu maior aproveitamento pelas plantas, mesmo quando as menores doses são empregadas ou que a distribuição do lodo seja realizada em área total. Dessa forma, não se justifica o aumento da dose de $\mathrm{N}$ visando ao aumento de produtividade. Além do mais, pode-se aumentar o risco de lixiviação de nitrato. SILVA et al. (1998), aplicando lodo de esgoto (0 a $30 \mathrm{t} \mathrm{ha}^{-1}$, base úmida) no fundo de um sulco com $15 \mathrm{~cm} \mathrm{de}$ profundidade e distando $40 \mathrm{~cm}$ da linha de cana-de-açúcar, encontraram aumento linear na produtividade da cana-de-açúcar (var. RB72-454).

Em todos os tratamentos estudados, tanto na cana-planta como na cana-soca, não foram verificados sintomas característicos de deficiência de nitrogênio - amarelecimento das folhas mais velhas. Resultados semelhantes foram encontrados por SILVA (1995), que enfatiza que o $\mathrm{N}$ fornecido pelo lodo de esgoto supriu a necessidade da cultura, principalmente para a cana-soca, com maior acúmulo de $\mathrm{N}$ na planta, o que refletiu em maior produtividade.

Nas Tabelas 3 e 4, estão apresentados os resultados médios obtidos para as variáveis agroindustriais da cana-planta e da cana-soca, em função dos fatores de variação estudados.

TABELA 3. Variáveis agroindustriais da cana-de-açúcar (cana-planta) cultivada após a aplicação de lodo de esgoto e vinhaça.

\begin{tabular}{lccccccc}
\hline & ${ }^{\circ}$ Brix & Pol caldo & Pureza & Pol cana & Fibra & AR $^{(1)}$ & ATR $^{(2)}$ \\
\hline Fertilização mineral & \multicolumn{2}{c}{$\%$ de caldo } & $\%$ & & $\%$ de cana & & $\mathrm{kg} \mathrm{t}^{-1}$ \\
Fatorial & 18,83 & 16,91 & 89,77 & 14,84 & 9,91 & 0,31 & 141,53 \\
Lodo de esgoto + KCl & 18,94 & 16,75 & 88,37 & 14,61 & 10,23 & 0,58 & 140,55 \\
Vinhaça + uréia & 18,95 & $16,81^{\mathrm{AB}}$ & $88,64^{\mathrm{A}}$ & 14,70 & 10,10 & $0,56^{\mathrm{B}}$ & 141,15 \\
Lodo de esgoto + vinhaça & 19,26 & $17,19^{\mathrm{A}}$ & $89,21^{\mathrm{A}}$ & 14,92 & 10,54 & $0,50^{\mathrm{B}}$ & 142,70 \\
Localizada & 18,57 & $16,21^{\mathrm{B}}$ & $87,19^{\mathrm{B}}$ & 14,20 & 10,01 & $0,69^{\mathrm{A}}$ & 137,67 \\
Área total & 18,88 & 16,72 & 88,46 & 14,55 & 10,37 & 0,58 & 139,91 \\
Dose 100\% & 18,98 & 16,77 & 88,27 & 14,67 & 10,08 & 0,59 & 141,19 \\
Dose 200\% & 19,23 & 17,14 & 89,07 & 14,91 & 10,43 & 0,52 & 142,70 \\
Teste F & 18,64 & 16,35 & 87,66 & 14,32 & 10,03 & 0,65 & 138,40 \\
Testemunha vs Fatorial & $0,05^{\mathrm{NS}}$ & $0,07^{\mathrm{NS}}$ & $2,13^{\mathrm{NS}}$ & $0,19^{\mathrm{NS}}$ & $0,43^{\mathrm{NS}}$ & $8,24^{* *}$ & $0,05^{\mathrm{NS}}$ \\
Resíduos & $2,36^{\mathrm{NS}}$ & $3,52^{*}$ & $5,39^{*}$ & $2,89^{\mathrm{NS}}$ & $2,57^{\mathrm{NS}}$ & $4,84^{*}$ & $2,23^{\mathrm{NS}}$ \\
Modo de aplicação & $0,18^{\mathrm{NS}}$ & $0,09^{\mathrm{NS}}$ & $0,13^{\mathrm{NS}}$ & $0,32^{\mathrm{NS}}$ & $2,47^{\mathrm{NS}}$ & $0,13^{\mathrm{NS}}$ & $0,55^{\mathrm{NS}}$ \\
Doses & $4,49^{*}$ & $5,80^{*}$ & $6,99^{*}$ & $4,32^{*}$ & $4,18^{*}$ & $6,54^{*}$ & $3,47^{*}$ \\
\hline C.V. (\%) & 4,32 & 5,72 & 1,81 & 5,45 & 6,89 & 28,43 & 4,52 \\
\hline
\end{tabular}

NS - não-significativo; * Diferença significativa a $5 \%$ de probabilidade - $\mathrm{p}<0,05$; ** Diferença significativa a $1 \%$ de probabilidade - $\mathrm{p}<0,01$; Médias seguidas de letras iguais ou sem letras não diferem entre si, pelo Teste de Tukey, a $5 \%$ de probabilidade; C.V. $(\%)$ - coeficiente de variação; ${ }^{(1)}$ AR: açúcar redutor; ${ }^{(2)}$ ATR: açúcar total recuperável.

Para a cana-soca (Tabela 4), não se observaram diferenças entre o tratamento com fertilização mineral e os demais. Quando se consideram os diferentes tipos de resíduos, os maiores valores de ${ }^{\circ}$ Brix são encontrados nas parcelas com aplicação exclusiva de vinhaça. Corroborando esses dados, CAMILOTTI et al. (2006) encontraram aumento no teor de Brix quando se aplicou vinhaça + uréia em doses para suprir a planta de cana-de-açúcar em $200 \%$ de K. O fornecimento de $\mathrm{K}$ favorece maior intensidade de síntese e acúmulo de sacarose (MALAVOLTA et al., 1989).

Observando-se os dados de pol caldo (\%) e pol cana (\%) para a cana-planta e a cana-soca, pode-se inferir que os colmos foram colhidos após atingirem o ponto de maturação. Segundo FERNANDES (2000), o teor de 14,4\% é considerado adequado para o início da colheita da canade-açúcar. Na cana-planta, da mesma forma que para o ${ }^{\circ}$ Brix caldo (\%), não houve diferença nas percentagens de pol caldo (\%) e pol cana (\%), entre as parcelas que receberam fertilizantes minerais e aquelas que receberam resíduos. No entanto, observou-se efeito do tipo de resíduo apenas na pol caldo (\%) no momento da colheita da cana-planta (Tabela 3). 
TABELA 4. Variáveis agroindustriais e resultados da análise de variância para cana-de-açúcar (cana-soca) cultivada por dois anos consecutivos, após a aplicação de lodo de esgoto e vinhaça.

\begin{tabular}{|c|c|c|c|c|c|c|c|}
\hline & ${ }^{\circ}$ Brix & Pol caldo & Pureza & Pol cana & Fibra & $\mathrm{AR}^{(1)}$ & $\mathrm{ATR}^{(2)}$ \\
\hline & \multicolumn{2}{|c|}{$\%$ de caldo } & $\%$ & \multicolumn{3}{|c|}{$\%$ de cana } & $\mathrm{kg} \mathrm{t}^{-1}$ \\
\hline Fertilização mineral & 22,8 & 20,4 & 89,8 & 16,4 & 15,0 & 0,41 & 155,89 \\
\hline Fatorial & 22,7 & 20,6 & 90,7 & 16,9 & 15,3 & 0,34 & 155,23 \\
\hline Lodo de esgoto $+\mathrm{KCl}$ & $22,6^{\mathrm{B}}$ & 20,6 & 91,4 & 18,0 & $14,8^{\mathrm{B}}$ & 0,31 & $156,69^{\mathrm{A}}$ \\
\hline Vinhaça + uréia & $23,1^{\mathrm{A}}$ & 20,6 & 89,8 & 16,5 & $15,3^{\mathrm{AB}}$ & 0,42 & $156,21^{\mathrm{A}}$ \\
\hline Lodo de esgoto + vinhaça & $22,5^{\mathrm{B}}$ & 20,5 & 91,0 & 16,2 & $15,8^{\mathrm{A}}$ & 0,31 & $152,78^{\mathrm{B}}$ \\
\hline Localizada & 22,7 & 20,7 & 91,2 & 17,4 & 15,5 & 0,30 & 155,37 \\
\hline Área total & 22,7 & 20,4 & 90,2 & 16,4 & 15,1 & 0,39 & 155,08 \\
\hline Dose $100 \%$ & 22,5 & 20,5 & 91,0 & 17,2 & 15,1 & 0,33 & 153,61 \\
\hline Dose $200 \%$ & 22,9 & 20,6 & 90,5 & 16,6 & 15,0 & 0,36 & 156,84 \\
\hline Teste F & & & & & & & \\
\hline Testemunha vs Fatorial & $0,20^{\mathrm{NS}}$ & $0,15^{\mathrm{NS}}$ & $0,58^{\mathrm{NS}}$ & $0,08^{\mathrm{NS}}$ & $0,35^{\mathrm{NS}}$ & $0,61^{\mathrm{NS}}$ & $0,08^{\mathrm{NS}}$ \\
\hline Resíduos & $8,20 * *$ & $0,46^{\mathrm{NS}}$ & $2,19^{\mathrm{NS}}$ & $1,58^{\mathrm{NS}}$ & $3,57 *$ & $2,05^{\mathrm{NS}}$ & $3,47 *$ \\
\hline Modo de aplicação & $0,09^{\mathrm{NS}}$ & $3,17^{\mathrm{NS}}$ & $2,38^{\mathrm{NS}}$ & $1,32^{\mathrm{NS}}$ & $2,23^{\mathrm{NS}}$ & $3,65^{\mathrm{NS}}$ & $0,05^{\mathrm{NS}}$ \\
\hline Doses & $8,56 * *$ & $0,62^{\mathrm{NS}}$ & $0,66^{\mathrm{NS}}$ & $0,48^{\mathrm{NS}}$ & $4,65^{*}$ & $0,52^{\mathrm{NS}}$ & $6,00 *$ \\
\hline C.V. (\%) & 1,68 & 2,47 & 2,09 & 15,73 & 5,90 & 22,53 & 2,54 \\
\hline
\end{tabular}

NS - não-significativo; * diferença significativa a $5 \%$ de probabilidade - p < 0,05; ** diferença significativa a $1 \%$ de probabilidade - $\mathrm{p}<0,01$; médias seguidas de letras iguais não diferem entre si, pelo Teste de Tukey, a $5 \%$ de probabilidade; C.V. (\%) - coeficiente de variação; ${ }^{(1)}$ AR: açúcar redutor; ${ }^{(2)}$ ATR: açúcar total recuperável.

A vinhaça apresentou maiores valores de pol caldo (\%) comparados com a aplicação de lodo de esgoto + vinhaça. O modo de aplicação dos resíduos não exercem qualquer efeito sobre as duas variáveis. Entretanto, o aumento da dose dos resíduos promove atraso na ascensão da pol na canaplanta. A utilização dos resíduos, independentemente da combinação estudada, resulta em concentração de sacarose na planta, nos mesmos níveis daqueles obtidos com a fertilização mineral. Resultados semelhantes foram encontrados por MARQUES (1996). Reduções nos teores de pol cana e pol caldo podem ser observados em CAMILOTTI et al. (2006) quando se aumentou em $100 \%$ a dose de $\mathrm{N}$ e K fornecidos via lodo de esgoto e via vinhaça, respectivamente, no $4^{\circ}$ corte da cana-de-açúcar.

Quanto aos açúcares redutores (AR), não foram observadas diferenças entre os tratamentos na cana-planta e na cana-soca, com exceção quanto ao tipo de resíduo na cana-planta (Tabela 3). Dentre os resíduos estudados, verificou-se que a associação lodo de esgoto + vinhaça proporcionou teores de açúcares redutores no caldo maiores do que os obtidos com a utilização isolada dos resíduos. O aumento da dose resulta em maiores teores de açúcares redutores, sendo indicativo da pemanência da cana por mais tempo em estágio vegetativo.

Quanto ao tipo de resíduo, considerando-se que a pol cana (\%) e os teores de açúcares redutores não foram influenciados pelos mesmos, e que a cana cultivada no solo que recebeu a mistura de lodo de esgoto + vinhaça, deveria ter sido mantida no campo por mais algum tempo, com a finalidade de incremento no teor de sacarose. Na cana-soca (Tabela 4), não se verificou efeito ocasionado pelos fatores de variação sobre o AR caldo (\%). Assim, a utilização dos resíduos em qualquer uma das combinações estudadas resulta em concentrações de açúcares redutores nos caldos nos mesmos níveis daqueles obtidos com a fertilização mineral. Resultados semelhantes foram encontrados por SILVA et al. (1998).

Segundo FERNANDES (2000), fibra é a matéria insolúvel em água contida na cana. $\mathrm{Na}$ cana-planta (Tabela 3), não se verificou efeito dos fatores de variação sobre a percentagem de fibra na cana, mesmo quando se aplicou o dobro da quantidade de $\mathrm{N}$ necessária à cultura. Esses resultados contrariam as expectativas de menores percentagens de fibra na cana, em decorrência de maior teor de água na planta (ORLANDO FILHO et al., 1995). Na cana-soca (Tabela 4), não foi 
observada diferença do tratamento-testemunha em relação ao fatorial. Quanto aos resíduos aplicados, as maiores percentagens de fibra são encontradas nas canas fertilizadas com vinhaça, seja ela acrescida de lodo de esgoto, seja de uréia. A alteração do modo de aplicação dos resíduos não proporcionou efeitos na \% de fibra. De outra forma, o aumento em $100 \%$ na dose resultou em menores teores de fibra na cana, assim como obtido por ORLANDO FILHO et al. (1995) e FIGUEIREDO (2000).

No Estado de São Paulo, essa variável deve ser de $10-11 \%$ para que seja recomendada a industrialização da cana (FERNANDES, 2000). A análise dos resultados de pureza para canaplanta (Tabela 3) indica que não houve diferenças entre caldos de canas fertilizadas com adubação mineral daquelas fertilizadas com os resíduos testados, assim como obtido por MARQUES (1996). Na $1^{\underline{a}}$ cana-soca (Tabela 4), a análise da pureza não revela diferença entre o tratamento-testemunha e o valor médio do fatorial, o mesmo ocorrendo entre os resíduos utilizados, a forma de aplicação e as doses utilizadas.

O ATR representa todos os açúcares na forma de açúcares invertidos (ART - açúcares redutores totais) que são recuperados na indústria, e é expresso em $\mathrm{kg} \mathrm{t}^{-1}$ de cana. Pelos resultados obtidos para cana-planta, verificou-se que os fatores de variação estudados não exerceram influência sobre o ATR. A média encontrada nas parcelas que receberam fertilizantes minerais, foi de $141,53 \mathrm{~kg} \mathrm{t}^{-1}$ frente aos $137,57 \mathrm{~kg} \mathrm{t}^{-1}$ obtidos nas parcelas que receberam lodo de esgoto + vinhaça, e 142,70 $\mathrm{kg} \mathrm{t}^{-1}$ naquelas que receberam apenas vinhaça. Para a cana-soca, dentre os fatores estudados, apenas o tipo de resíduo e a dose proporcionam alterações nos valores de ATR. O uso de lodo de esgoto $+\mathrm{KCl}$ ou vinhaça + uréia resultou em teores de ATR maiores do que os obtidos nas parcelas que receberam os dois resíduos associados. Esses resultados são discordantes dos obtidos por SILVA et al. (1998), em que os autores não detectaram efeitos do aumento das doses de lodo de esgoto sobre os teores de ATR.

Observando a produtividade do ATR para cana-planta (Tabela 3), não se verificou efeito dos fatores de variação. Assim, a não-ocorrência de diferença entre as parcelas da fertilização mineral e aquelas integrantes do esquema fatorial permite a inferência de que a aplicação de lodo de esgoto + vinhaça ou $\mathrm{KCl}$, na cultura da cana-de-açúcar, pode substituir a adubação mineral convencional, sem prejuízos na produtividade de açúcar - parâmetro principal no pagamento da cana-de-açúcar pela qualidade.

\section{CONCLUSÕES}

As produtividades de colmo e de açúcar para cana-planta são mantidas quando o $\mathrm{N}$ e o K são fornecidos pelo lodo de esgoto e vinhaça, respectivamente.

A cana-soca apresentou maior produtividade de colmo e de açúcar quando foram utilizados os resíduos separadamente, complementados com fontes minerais.

\section{REFERÊNCIAS}

ABREU JÚNIOR, C.H.; BOARETTO, A.E.; MURAOKA, T.; KIEHL, J.C. Uso agrícola de resíduos orgânicos: propriedades químicas do solo e produção vegetal. In: VIDAL-TORRADO, P.; ALLEONI, L.R.F.; COOPER, M.; SILVA, A.P.; CARDOSO, E.J. Tópicos em Ciência do Solo IV. Viçosa: SBCS, 2005. p.391-470.

ANDREOLI, C.V.; DOMASZAK, S.; FERNANDES, F.; LARA, A.I. Proposta preliminar de regulamentação para reciclagem agrícola do lodo de esgoto no Paraná. Sanare, Curitiba, v.7, n.7, p.53-60, 1997.

BUZOLIN, P.R.S. Efeitos da palha residual da colheita mecanizada, associada a fontes de potássio e doses de nitrogênio, no solo e nas socas de cana-de-açúcar. 1997.98 f. Dissertação (Mestrado em Produção Vegetal) - Faculdade de Ciências Agrárias e Veterinárias, Universidade Estadual Paulista, Jaboticabal, 1986. 
CAMILOTTI, F.; ANDRIOLI, I.; MARQUES, M.O.; SILVA, A.R.; TASSO JUNIOR, L.C.; NOBILE, F.O. NOGUEIRA, G.A.; PRATI, F. Produtividade e qualidade agroindustrial da canade-açúcar cultivada com lodo de esgoto, vinhaça e adubos minerais. STAB: Açúcar, Álcool e Subprodutos, Piracicaba, v.24, n.3, p.32-35, 2006.

CHIBA, M.K. Uso de lodo de esgoto na cana-de-açúcar como fonte de nitrogênio e fósforo: parâmetros de fertilidade do solo, nutrição da planta e rendimentos da cultura. 2005. 142f. Tese (Doutorado em Solos e Nutrição de Plantas) - Escola Superior de Agricultura "Luiz de Queiroz", Universidade de São Paulo, Piracicaba, 2005.

CONSECANA. Manual de instruções. 4. ed. Piracicaba: Opinião, 2003. 116 p.

FERNANDES, A.C. Cálculos na agroindústria da cana-de-açúcar. Piracicaba: STAB - Açúcar, Álcool e Subprodutos, 2000. 193 p.

FIGUEIREDO, P.A.M. Efeitos da vinhaça e de sua complementação nitrogenada e biológica no palhiço, no solo e na cana-de-açúcar. 2000. 77 f. Tese (Doutorado em Fitotecnia) - Universidade Federal de Lavras, Lavras, 2000.

FRANKLIN, R. Land application of sewage sludge. Faculty of Soils and Land Resources. Clemson University, 2004. 16 p.

MALAVOLTA, E.; VITTI, G.C.; OLIVEIRA, S.A. Avaliação do estado nutricional das plantas. Princípio e aplicações. Piracicaba: Associação Brasileira para a Pesquisa da Potassa e do Fosfato, 1989. $201 \mathrm{p}$.

MARQUES, M.O. Incorporação de lodo de es goto em solo cultivado com cana-de-açúcar. 1996. 111 f. Tese (Livre-Docência) - Faculdade de Ciências Agrárias e Veterinárias, Universidade Estadual Paulista, Jaboticabal, 1996.

MELO, W.J.; MARQUES, M.O.; MELO, V.P. O uso agrícola do biossólido e as propriedades do solo. In: TSUTIYA, M.T.; COMPARINI, J.B.; SOBRINHO, P.A.; HESPANOL, I.; CARVALHO, P.C.T.; MELFI, A.J.; MELO, W.J.; MARQUES, M.O. Biossólidos na agricultura. São Paulo: SABESP, 2001. p.289-363.

OLIVEIRA, F.C. Disposição de lodo de esgoto e composto de lixo urbano num Latossolo Vermelho-Amarelo cultivado com cana-de-açúcar. 2000. $247 \mathrm{f}$. Tese (Doutorado em Solos e Nutrição de Plantas) - Escola Superior de Agricultura "Luiz de Queiroz", Universidade de São Paulo, Piracicaba, 2000.

ORLANDO FILHO, J.; ZAMBELLO JÚNIOR, E.; AGUJARO, R; ROSSETO, A.L.J. Efeitos da aplicação prolongada de vinhaça nas propriedades químicas dos solos com cana-de-açúcar. Estudo exploratório. STAB - Açúcar, Álcool e Subprodutos, Piracicaba, v.1, n.1, p.28-33, 1983.

ORLANDO FILHO, J.; BITTENCOURT, V.C.; ALVES, M.C. Aplicação de vinhaça em solos arenosos do Brasil e poluição do lençol freático com nitrogênio. STAB - Açúcar, Álcool e Subprodutos, Piracicaba, v.13, n.6, p.14-16, 1995.

RAIJ, van B.; CANTARELLA, H.; QUAGGIO, J.A.; FURLANI, A.M.C. Recomendações de adubação e calagem para o Estado de São Paulo. Campinas: IAC, 1996 (Boletim Técnico, 100).

SILVA, F.C. da. Uso agronômico de lodo de esgoto: efeitos em fertilidade do solo e qualidade da cana-de-açúcar. 1995. 159 f. Tese (Doutorado em Solos e Nutrição de Plantas) - Escola Superior de Agricultura "Luiz de Queiroz", Universidade de São Paulo, Piracicaba, 1995.

SILVA, F.C.; BOARETTO, A.E.; BERTON, R.S.; ZOTELLI, H.B.; PEXE, C.A.; MENDONÇA, E. Cana-de-açúcar cultivada em solo adubado com lodo de esgoto: nutrientes, metais pesados e produtividade. Pesquisa Agropecuária Brasileira, Brasília, v.33, n.1, p.1-8, 1998.

SPIRONELLO, A.; RAIJ, B. van; PENATTI, C.P.; CANTARELLA, H.; MORELLI, J.L.; ORLANDO FILHO, J.; LANDELL, M.G.A.; ROSSETO, R. Cana-de-açúcar. In: RAIJ, B. van; CANTARELLA, H.; QUAGGIO, J.A.; FURLANI, A.M.C. 2 ed. rev. atual. Recomendações de adubação e calagem para o Estado de São Paulo. Campinas: Instituto Agronômico/Fundação IAC, 1997. p.237-9. (Boletim Técnico, 100). 